\title{
Hydrothermal synthesis, characterization and dielectric properties of zirconia nanoparticles
}

\begin{abstract}
Simple hydrothermal method has been used to synthesize zirconia $\left(\mathrm{ZrO}_{2}\right)$ nanoparticles in alkaline medium. The powder X-ray diffraction technique (PXRD), electron microscopic studies (SEM and TEM) and BET surface area studies were done to characterize the as-synthesized nanoparticles. The crystalline nature and phase analysis of the $\mathrm{ZrO}_{2}$ nanoparticles was determined by X-ray diffraction studies which revealed that the as-synthesized powder is pure monoclinic zirconia $\left(\mathrm{m}-\mathrm{ZrO}_{2}\right)$. The particle size was estimated by TEM and HRTEM studies, which comes out to be about $25 \mathrm{~nm}$. The surface area of as-prepared $\mathrm{ZrO}_{2}$ nanoparticles was found to be $186 \mathrm{~m}^{2} / \mathrm{g}$ with DA pore radius of $11.9 \AA$ by using BET surface area studies. The dielectric constant and dielectric loss of the nanoparticles were found to be 7.5 and 0.0094 for as-synthesized nanoparticles at $500 \mathrm{kHz}$ frequency at room temperature.
\end{abstract}

\author{
Volume I Issue 3- 2017
}

Tokeer Ahmad, Mohd Shahazad, Ruby Phul
Department of Chemistry,Jamia Millia Islamia, India

Correspondence: Tokeer Ahmad, Department of Chemistry, Jamia Millia Islamia, India, Tel 9I-II-2698I7I7,

Email tahmad3@jmi.ac.in

Received: September 01, 2017 | Published: October 13, 2017

\section{Introduction}

The solid materials have wide applications in many fields owing to defects in their crystal structure. The material when manipulated up to nano size then it exhibits properties very different as compared to micro size particles of the same material. Nano sized transition metal oxides have been considered gifted materials having their applications in industry, medicine and in various other fields. The metal oxide nanoparticles have attracted special attention to design nano structures for a variety of applications because of their enhanced physical and chemical properties. ${ }^{1}$ The oxide nanoparticles are used to design energy efficient lithium ion batteries, ${ }^{2,3}$ light emitting diodes, ${ }^{4,5}$ solar cells, ${ }^{6,7}$ fuel cells ${ }^{8,9}$ and transistors, ${ }^{10,11}$ hydrogen storage devices, ${ }^{12,13}$ air purification, ${ }^{14}$ water purification, ${ }^{15}$ gas sensing, ${ }^{16}$ temperature and humidity sensing studies, ${ }^{17}$ drug delivery and bio imaging studies. ${ }^{18,19}$

The nano sized $\mathrm{ZrO}_{2}$ is very interesting and valuable material for its fundamental and application based properties. $\mathrm{ZrO}_{2}$ is known to exist in three crystalline forms monoclinic, tetragonal and cubic structures. Thermodynamically most stable form of $\mathrm{ZrO}_{2}$ is monoclinic. The cubical form of $\mathrm{ZrO}_{2}$ is stable at high temperature (above 2370C), tetragonal form is stable between $1170-2370^{\circ} \mathrm{C}$ whereas monoclinic $\mathrm{ZrO}_{2}$ is stable below $1170^{\circ} \mathrm{C} .{ }^{20} \mathrm{ZrO}_{2}$ is well known refractory oxide and a potential candidate as high $\mathrm{k}$-gate dielectric material. To select any material as gate oxide applications, the first and very important requirement is high dielectric constant value. The material possessing too high dielectric constant value, such as for $\mathrm{TiO}_{2}(\sim 80)$, fringing fields from the drain through the gate dielectric are observed which may degrade the source to channel potential barrier and may lead to poor sub-threshold device functioning. ${ }^{13-21}$ Pure zirconia has been known to exhibit anionic vacancies defects predominantly. The nano sized zirconia owing to large surface area has high number of oxygen vacancies at grain surfaces. ${ }^{22}$ Therefore solid $\mathrm{ZrO}_{2}$ can conduct electricity up to some extent and it is considered as p-type semiconductor. The band gap value of $\mathrm{ZrO}_{2}$ depends upon synthesis temperature, particle size and crystalline structure. The value of band gap for tetragonal form has been reported more than that monoclinic which in turn has higher band gap value than that of cubic form. ${ }^{23} \mathrm{~A}$ number of binary oxides such as $\mathrm{TiO}_{2}, \mathrm{Y}_{2} \mathrm{O}_{3}, \mathrm{ZrO}_{2}$ and some perovskites materials such as $\mathrm{SrTiO}_{3}, \mathrm{BaZrO}_{3}, \mathrm{Ba}_{(1-\mathrm{x})} \mathrm{Sr}_{\mathrm{x}} \mathrm{ZrO}_{3}$ and $\mathrm{Ba}_{(1-\mathrm{x})} \mathrm{Sr}_{\mathrm{x}} \mathrm{ZrO}_{3}$ have been studied as dielectric oxide material for complementary metal oxide semiconductor (CMOS) devices ${ }^{24-27}$ but $\mathrm{ZrO}_{2}$ have been investigated extensively as potential candidate for dynamic random access memory devices (DRAM) owing to its moderately high dielectric constant $(\mathrm{k}=20)$ and higher thermal stability. ${ }^{28}$ Numerous chemical methods have been reported to synthesize pure $\mathrm{ZrO}_{2}$, such as thermal decomposition, ${ }^{20}$ sol-gel methods, ${ }^{29}$ reverse micellar method ${ }^{30,31}$ and hydrothermal techniques. ${ }^{32}$ In this paper we have synthesized the single phase $\mathrm{ZrO}_{2}$ nanoparticles to check their applications as dielectric material as a function of frequency and temperature. The as-prepared nanoparticles were extensively characterized using PXRD, SEM, TEM and BET surface area studies.

\section{Experimental section}

The chemicals hydrated zirconium oxy nitrate (Alpha Aesar, 99.9\%), sodium hydroxide (Merck, 99\%) were used as such without further purification. The double distilled water was used throughout the experiment.

The synthesis of $\mathrm{ZrO}_{2}$ nanoparticles have been processed using typical hydrothermal method. $0.1 \mathrm{M} \mathrm{ZrO}\left(\mathrm{NO}_{3}\right)_{2} \cdot \mathrm{xH}_{2} \mathrm{O}$ and $0.2 \mathrm{M} \mathrm{NaOH}$ were prepared in double distilled water. Equal volumes $(25 \mathrm{ml}$ of each solutions) were mixed in order to form a 1:2 molar ratio solution of $\mathrm{ZrO}\left(\mathrm{NO}_{3}\right)_{2} \cdot \mathrm{xH}_{2} \mathrm{O}$ and $\mathrm{NaOH}$. The solution obtained were transferred in to the hydrothermal flask and placed in oven for heating at $150^{\circ} \mathrm{C}$ for 4 hours. To collect the precipitates, the solution was centrifuged for 5 minutes at $8000 \mathrm{rpm}$ and washed with acetone several times. The precipitates were then dried in vacuum oven at $110^{\circ} \mathrm{C}$ for 90 minutes and grinded to obtain fine powder of $\mathrm{ZrO}_{2}$ nanoparticles.

\section{Characterization}

The crystalline structure of as-synthesized nanoparticles was determined with the help of Rigaku ultima IV X-ray Diffractometer with $\mathrm{Cu}$ target and $(\lambda)=1.5416 \AA$. Powder X-ray diffraction patterns were recorded in $10-80^{\circ} 2 \theta$ scanning range with scanning rate of $0.05^{\circ}$ per second. The morphology of the nanoparticles was determined by scanning electron microscope FEI SEM (Model: Nova Nano SEM 
450, Hillsboro, OR). The powder obtained after grinding the sintered pellet was used to get SEM images at various magnifications. The average particle size of as-synthesized $\mathrm{ZrO}_{2}$ nanoparticles was determined by transmission electron microscope FEI Technai $\mathrm{G}^{2} 20$ TEM by using accelerating voltage of $200 \mathrm{kV}$. TEM specimen was prepared using fine powder form of the sample. The nanopowder was dispersed in absolute ethanol and sonicated by an ultrasonic bath for 30 minutes. The dispersed sample was placed on a carbon coated copper grid with the help of micropipette. The grid was dried at $100^{\circ} \mathrm{C}$ for 1 hour. BET surface area analyzer (Model: Nova 2000e, Quantachrome Instruments Limited, Boynton Beach, FL) was used for surface area studies of the sample. The specific surface area of as-synthesized $\mathrm{ZrO}_{2}$ nanoparticles was determined using "Multipoint BET Method" at $77 \mathrm{~K}$. Before analysis for specific surface area, $0.05 \mathrm{~g}$ of the sample was degassed in vacuum degassing mode for 3 hours at $250^{\circ} \mathrm{C}$ to take out absorbed water vapours and gaseous contaminations. A known amount of adsorbing $\mathrm{N}_{2}$ gas got admitted into the sample cell having powder adsorbent. In the sample cell, the pressure changes to get equilibrated during the adsorption. The absorption plot was used to compute the specific surface area of the sample by using BET principle. Dielectric measurements of as-synthesized nanoparticles were performed with the help of high frequency LCR meter (Model: 6505P; Make: Wayne Kerr, UK). Before performing the dielectric measurements, the diameter and thickness of the pellets were measured and area of pellets was calculated. The capacitance and dielectric loss were recorded by using sintered pellet of the sample and dielectric constant value was find out from the measured capacitance of the sample.

\section{Results and discussion}

The phase purity and the crystal structure of as-prepared nanoparticles were identified by Powder X-ray diffractometer. Figure 1 represents the diffraction pattern for zirconia nanoparticles which is indexed as monoclinic $\mathrm{ZrO}_{2}\left(\mathrm{~m}-\mathrm{ZrO}_{2}\right)$ and are in good agreement with the standard JCPDS no. 83-0936. The diffraction pattern shows sharp and well defined peaks which indicate the highly crystalline nature as well as purity of the sample. Thus on the basis of X-ray diffraction studies, it has to be concluded that pure monophasic $\mathrm{ZrO}_{2}$ powder was prepared by using the prescribed method as discussed in experimental section.

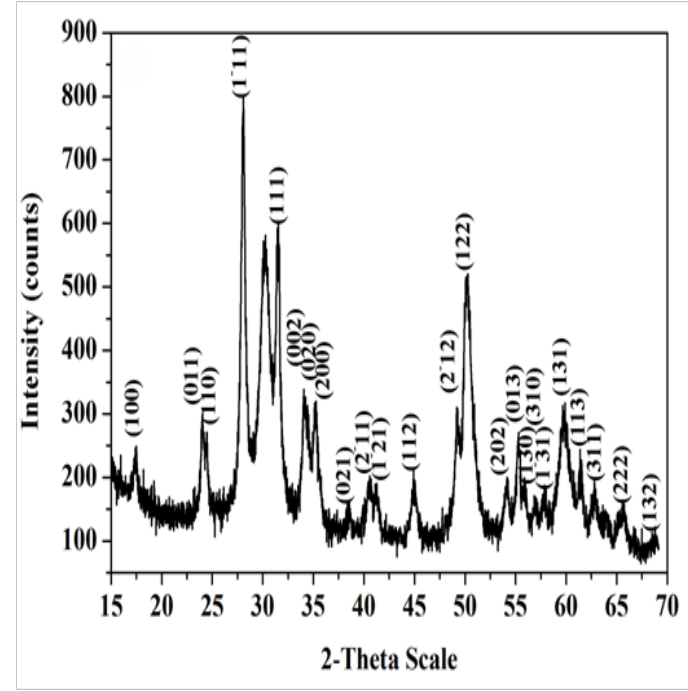

Figure I X-ray diffraction pattern of $\mathrm{ZrO}_{2}$ nanoparticles.
The surface morphology of the as-acquired zirconia nanoparticles was investigated by scanning electron microscopy as shown in Figure 2. SEM image clearly indicates that the zirconia nanoparticles has smooth surface with small particle size. The agglomeration of nanoparticles is also visible in the SEM images.

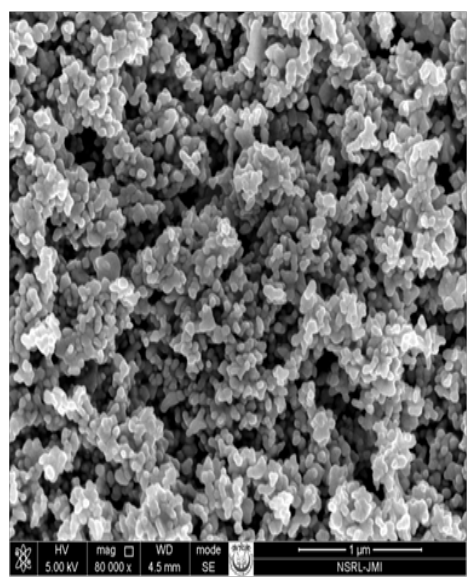

Figure 2 Scanning electron microscopic image $\mathrm{ZrO}_{2}$ nanoparticles.

The shape and size of the as-prepared nanoparticles have been estimated from transmission electron microscopic (TEM) studies. The TEM micrographs of zirconia nanoparticles are shown in Figure 3A. The micrograph shows that the particles are uniform in size and the small spheres tend to form cubic shape. The average size estimated from these micrographs was found to be $25 \mathrm{~nm}$. The transmission electron micrograph is in good agreement with the SEM image. Figure 3B represent HRTEM image of as-synthesized monoclinic $\mathrm{ZrO}_{2}$ nanoparticles. The HRTEM micrograph visualizes well-resolved lattice fringes at a distance of $2.84 \pm 0.04 \AA$ which can be accredited to the inter-planar spacing corresponding to (111) plane..$^{33}$ The parallel fringes were found to be equidistant authenticate single phase nanocrystalline grains of monoclinic $\mathrm{ZrO}_{2}$. The selectedarea electron diffraction (SAED) pattern of zirconia nanoparticles is shown in figure $3 \mathrm{c}$ which demonstrates the different lattice planes of $\mathrm{m}-\mathrm{ZrO}_{2}\left({ }^{-} 111\right),(111),(122)$ and (131) in the SAED pattern which are in good agreement with the XRD pattern.

The specific surface area of the as-acquired nanoparticles was determined by the Brunauer-Emmett-Teller (BET) gas adsorption method $^{34}$ and the pore radius and pore volume was calculated using Barrett-Joyner-Halenda (BJH) method. ${ }^{35}$ Figure 4 shows the BET plots of zirconia nanoparticles. The specific surface area calculated using the multipoint BET equation was found to be $186 \mathrm{~m}^{2} \mathrm{~g}^{-1}$. Pore size distribution plot of as-synthesized nanoparticles is shown in Figure 5 and 6 . The pore radius of these nanoparticles was calculated using BJH method as well as DA method and presented in Table 1 with the corresponding pore volumes.

The dielectric properties of as synthesized nanoparticles were studied as a function of frequency after sintering the pellets at $1000^{\circ} \mathrm{C}$ for 10 hours. The dielectric constant is estimated by using the formula. ${ }^{36}$

$$
\varepsilon^{\prime}=C d / \varepsilon_{0} A
$$

Where $\mathrm{C}$ is capacitance of pellet, $\mathrm{d}$ the thickness of pellet, $\mathrm{A}$ the cross-sectional area of the flat surface of the pellet and $\varepsilon_{0}$ the permittivity for free space. 
The dielectric characteristics including the dielectric constant and loss factor were determined with variation of frequency in a range from $20 \mathrm{KHz}$ to $1 \mathrm{MHz}$ at room temperature as shown in Figure 7. Figure 7 shows that the dielectric constant decreases with increase in frequency. On account of space polarization effect, the zirconia nanoparticle shows high dielectric constant at lower frequency region. However, at higher frequency region the polarization effect reduces which raises the decrease in dielectric constant. ${ }^{37}$ The room temperature dielectric constant and dielectric loss values were found to be 7.5 and 0.0094 for the as synthesized nanoparticles at $500 \mathrm{kHz}$.
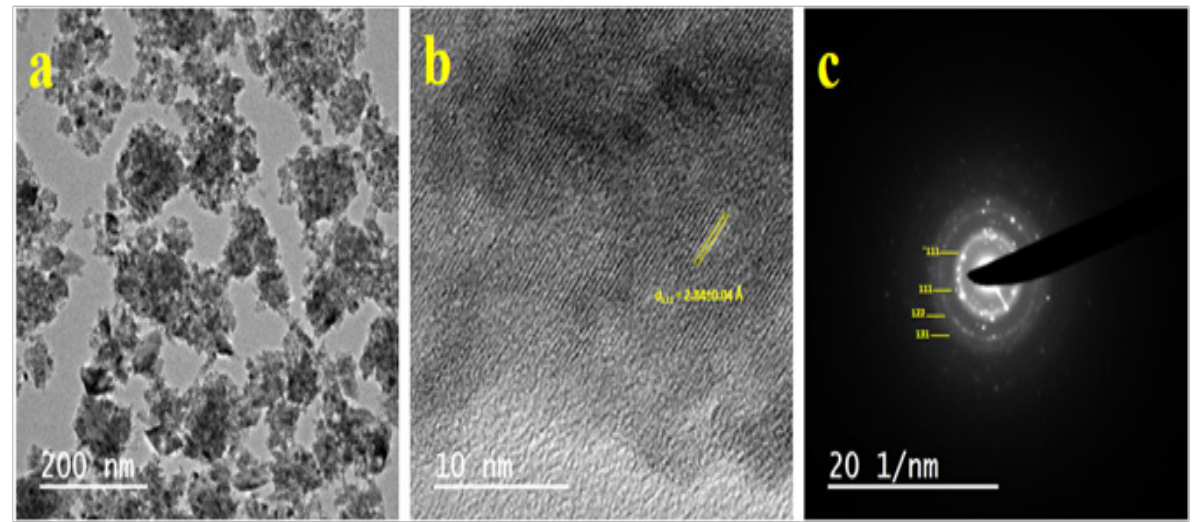

Figure 3 (a) Transmission electron micrograph, (b) HRTEM image and (c) SAED pattern of $\mathrm{ZrO}_{2}$ nanoparticles.

Table I BET surface area, BJH and DA pore radius parameters of as-synthesized nanoparticles

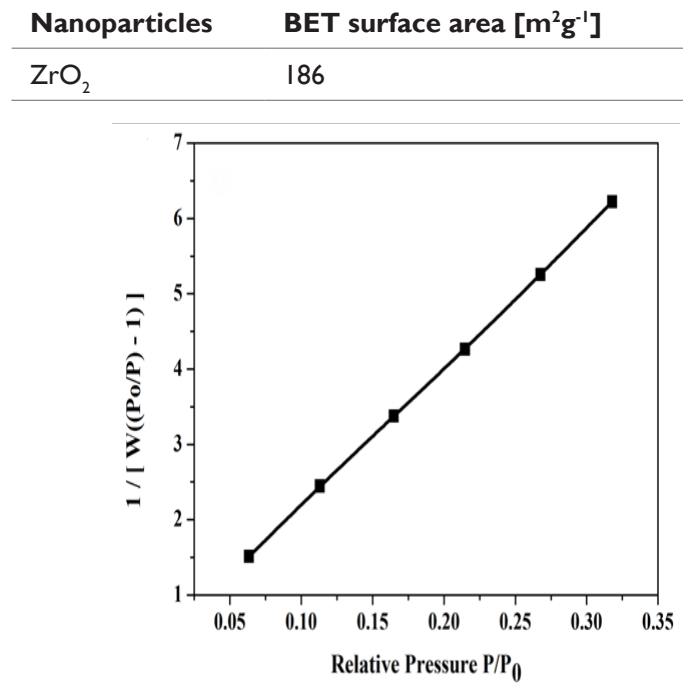

Figure 4 BET plot of $\mathrm{ZrO}_{2}$ nanoparticles.

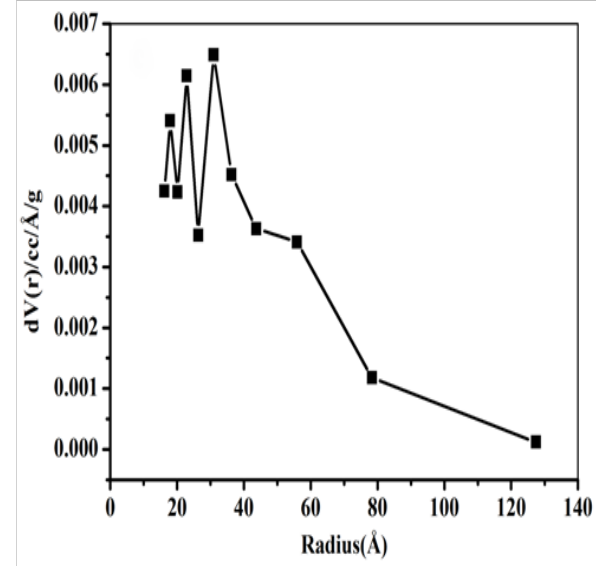

Figure $5 \mathrm{BJH}$ pore radius plot of $\mathrm{ZrO}_{2}$ nanoparticles.

\begin{tabular}{lll} 
BJH pore radius $[\mathrm{A}]$ & DA pore radius $[\mathrm{A}]$ & Pore volume $\mathbf{c m}^{3} \mathbf{g}^{-1}$ \\
\hline 30.9 & 11.9 & 0.247 \\
\hline
\end{tabular}

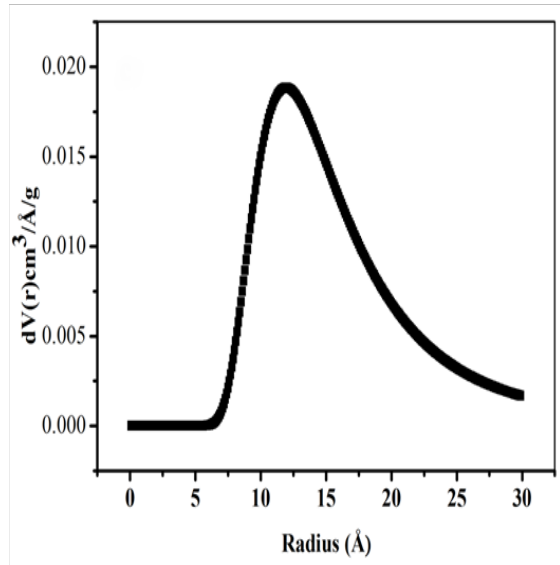

Figure $6 \mathrm{DA}$ pore radius plot of $\mathrm{ZrO}_{2}$ nanoparticles.

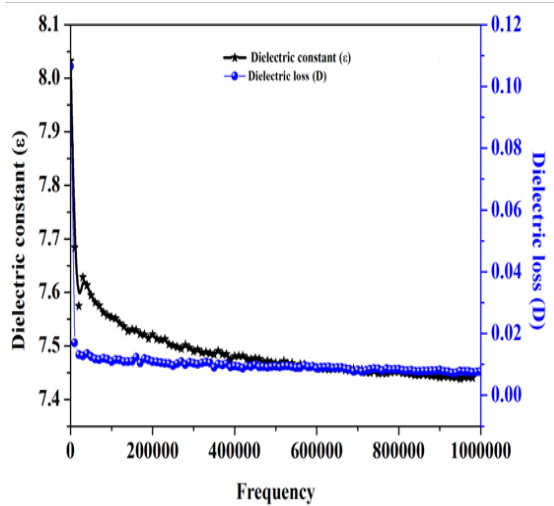

Figure 7 Dielectric constant and dielectric loss of $\mathrm{ZrO}_{2}$ nanoparticles at room temperature. 


\section{Conclusion}

Zirconia nanoparticles were synthesized by the simple hydrothermal method in alkaline medium at $150^{\circ} \mathrm{C}$. X-ray diffraction, HRTEM and SAED analysis confirms that the synthesized nanoparticles are pure monoclinic phase of $\mathrm{ZrO}_{2}$. The diameters/particle size of the $\mathrm{m}-\mathrm{ZrO}$ nanoparticles fell into range of $25 \mathrm{~nm}$ with the specific surface area of $186 \mathrm{~m}^{2} \mathrm{~g}^{-1}$. The SEM image is in accordance with the TEM micrograph. The dielectric properties of $\mathrm{m}-\mathrm{ZrO}_{2}$ nanoparticles make them a suitable material for the storage devices and electronic devices. These nanoparticles can also be used for photonic applications, gas sensors and solid oxide fuel cells.

\section{Acknowledgements}

TA thanks to CSIR, Govt. of India for financial support of the research project (No. 01(2897)/17/EMR-II). The authors thank CIF, Jamia Millia Islamia for X-Ray diffraction studies and JNCASR, Bangalore for electron microscopic studies. MS and RP especially thanks to UGC, New Delhi for Research Fellowship.

\section{Conflict of interest}

The author declares no conflict of interest

\section{References}

1. Zhai T, Fang X, Liao M, et al. A comprehensive review of one-dimensional metal-oxide nanostructure photodetectors. Sensors. 2009;9(8):65046529.

2. Poizot P, Laruelle S, Grugeon S, et al. Nano-sized transition-metal oxides as negative-electrode materials for lithium-ion batteries. Nature. 2000;407:496-499.

3. Huang H, Kelder EM, Schoonman J. Graphite-metal oxide composites as anode for Li-ion batteries. Journal of Power Sources. 2001;97:114 117

4. Kim BJ, Ryu YR, Lee TS, et al. Output power enhancement of GaN light emitting diodes with p-type $\mathrm{ZnO}$ hole injection layer. Applied Phys Lett. 2009;94(10):103506(1-3)

5. Park WI, Yi GC. Electroluminescence in $\mathrm{n}-\mathrm{ZnO}$ Nanorod Arrays Vertically Grown on p-GaN. Adv Mater. 2004;16(1):87-90.

6. Snaith HJ, Mende LS. Advances in liquid-electrolyte and solid-state dye-sensitized solar cells. Adv Mater. 2007;19(20):3187-3200.

7. Gratzel M. Photoelectrochemical cells. Nature. 2001;414:338-344.

8. Asamoto M, Miyake S, Sugihara K, et al. Improvement of Ni/SDC anode by alkaline earth metal oxide addition for direct methane-solid oxide fuel cells. Electrochemistry Communications. 2009;11(7):1508-1511.

9. Mamak M, Coombs N, Ozin G. Self-assembling solid oxide fuel cell materials: mesoporous yttria-zirconia and metal-yttria-zirconia solid solutions. Journal of the American Chemical Society. 2000;122(37):89328939.

10. Sun B, Sirringhaus H. Solution-processed zinc oxide field-effect transistors based on self-assembly of colloidal nanorods. Nano Lett. 2005;5(12):2408-2413.

11. Norris BJ, Anderson J, Wager JF, et al. Spin-coated zinc oxide transparent transistors. Journal of Physics D: Applied Physics. 2003;36(20):105107

12. Im JS, Park SJ, Kim T, et al. Hydrogen storage evaluation based on investigations of the catalytic properties of metal/metal oxides in electrospun carbon fibers. International Journal of Hydrogen Energy. 2009;34(8):3382-3388.
13. Panda D, Tseng TY. Growth, dielectric properties, and memory device applications of $\mathrm{ZrO}_{2}$ thin films. Thin Solid Films. 2013;531:1-20.

14. Quintana M, Ricra E, Rodriguez J, et al. Spray pyrolysis deposited zinc oxide films for photo-electrocatalytic degradation of methyl orange: influence of the pH. Catalysis Today. 2002;76(2-4):141-148.

15. Hepel M, Hazelton S. Photoelectrocatalytic degradation of diazo dyes on nanostructured $\mathrm{WO}_{3}$ electrodes. Electochim Acta. 2005;50(2526):5278-5291.

16. Rout CS, Hegde M, Govindaraj A, et al. Ammonia sensors based on metal oxide nanostructures. Nanotech. 2007;18(20):205504(1-9).

17. Zhao S, Wei P, Chen S. Enhancement of trimethylamine sensitivity of MOCVD-SnO thin film gas sensor by thorium. Sensors and Actuators B: Chemical. 2000;62(2):117-120.

18. Bae S, Lee SW, Takemura Y. Applications of $\mathrm{NiFe}_{2} \mathrm{O}_{4}$ nanoparticles for a hyperthermia agent in biomedicine. Appl Phys Lett. 2006;89(25):252503.

19. Stoeva SI, Lee JS, Smith JE, et al. Multiplexed detection of protein cancer markers with biobarcoded nanoparticle probes. Journal of the American Chemical Society. 2006;128(26):8378-8379.

20. Vaidya S, Ahmad T, Agarwal S, et al. Nanocrystalline oxalate/carbonate precursors of $\mathrm{Ce}$ and $\mathrm{Zr}$ and their decompositions to $\mathrm{CeO}_{2}$ and $\mathrm{ZrO}_{2}$ nanoparticles. Journal of the American Ceramic Society. 2007;90(3):863869.

21. Wong YH, Cheong KY. $\mathrm{ZrO}_{2}$ thin films on Si substrate. Journal of Mate rials Science: Materials in Electronics. 2010;21(10):980-993.

22. Kumar CSSR. Nanomaterials-Toxicity, Health and Environmental Issues (1). Germany: Wiley-VCH; 2006.

23. Jiang H, Gomez-Abal RI, Rinke P, et al. Electronic band structure of zirconia and hafnia polymorphs from the GW perspective. Phys Review B. 2010;81(8):085119 (1-9).

24. Yoon KR, Im KV, Yeo JH, et al. SSDM Extended Abstracts. 2002:188.

25. Ubaidullah M, Lone IH, A1-Hartomy OA, et al. Metal organic precursor route for $\mathrm{Pb}$-substituted $\mathrm{BaZrO}_{3}$ nanoceramics: structural characterization and properties. Adv Sci Lett. 2014;20(7-9):1354-1359.

26. Al-Hartomy OA, Ubaidullah M, Kumar D, et al. Dielectric properties of $\mathrm{Ba}_{1-\mathrm{x}} \mathrm{Sr}_{\mathrm{x}} \mathrm{ZrO}_{3}(0 \leq \mathrm{x} \leq 1)$ nanoceramics developed by citrate precursor route. J Mater Res. 2013;28(8):1070-1077.

27. Al-Hartomy OA, Ubaidullah M, Khatoon S, et al. Synthesis, characterization and dielectric properties of nanocrystalline $\mathrm{Ba}_{1 \times} \mathrm{Pb}_{\mathrm{ZrO}}$ $(0 \leq \mathrm{x} \leq 0.75)$ by polymeric citrate precursor route. J Mater Res. 2012;27(19):2479-2488.

28. Chen HI, Chang HY. Synthesis of nanocrystalline cerium oxide particles by the precipitation method. Ceram Int. 2005;31(6):795-802.

29. Zhang YW, Yan ZG, Liao FH, Citrate gel synthesis and characterization of $\left(\mathrm{ZrO}_{2}\right)_{085}\left(\mathrm{REO}_{15}\right)_{015}(\mathrm{RE}=\mathrm{Y}, \mathrm{Sc})$ solid solutions. Mater Res Bull. 2004;39(11):1763-1777.

30. Ahmad T, Ganguli AK. Structural and dielectric characterization of nanocrystalline $(\mathrm{Ba}, \mathrm{Pb}) \mathrm{ZrO}_{3}$ developed by reverse micellar synthesis. $J \mathrm{Am}$ Ceram Soc. 2006;89(10):3140-3146.

31. Ahmad T, Ganguli AK. Synthesis, characterization and dielectric properties of nanometer-sized particles of strontium zirconate prepared through a modified reverse micellar route. Mater Lett. 2006;60(29-30):3660 3663.

32. Kumari L, Du GH, Li WZ, et al. Synthesis, microstructure and optical characterization of zirconium oxide nanostructures. Ceram Int. 2009;35(6):2401-2408. 
33. Zhao N, Pan D, Nie W, et al. Two-phase synthesis of shape-controlled colloidal zirconia nanocrystals and their characterization. J Am Chem Soc. 2006;128(31):10118-10124.

34. Brunauer S, Emmett PH, Teller E. Adsorption of gases in multimolecular layers. J Am Chem Soc. 1938;60(2):309-319.

35. Barrett EP, Joyner LG, Halenda PP. The determination of pore volume and area distributions in porous substances. i. computations from nitrogen isotherms. J Am Chem Soc. 1951;73(1):373-380.
36. Von Hippel R. Dielectric materials and applications. USA: Technology Press of MIT and John Wiley; 1954. p. 1-438.

37. Babu R, Reddy NRM, Reddy K. Synthesis and characterization of high dielectric nano zirconium oxide. Ceramics International. 2015;41(9):10675-10679. 